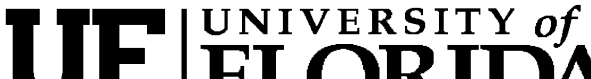 FLORIDA \\ IFAS Extension
}

\section{The Role of Humans in Poultry Disease Outbreaks ${ }^{1}$}

\section{Gary Butcher and Mojtaba Yegani ${ }^{2}$}

The commercial poultry industry has grown considerably in most areas of the world over the past 20 years. With the increase in size and complexity of poultry operations (broilers, layers and breeders), managers have been forced to focus more effort on disease prevention. The risk of disease outbreaks continues to be a major concern to the poultry industry and any doubters need only look back over the recent Bird Flu crisis to see the effects of a disease on profitability. The movement of people (e.g. farm employees and visitors) and birds, eggs, and feed among farms, has meant that the potential for spread of diseases is still significant. The objective of this article is to focus on the roles people may play in the occurrence of diseases and what should be done to reduce or minimize the effects of this potential risk factor.

\section{Humans: The Main Culprits}

Humans, in direct or indirect contact with poultry, are the primary route of introduction or spread of diseases among poultry farms. Mobility, tasks (as employee, manager or veterinarian), curiosity, lack of knowledge, and negligence are among the factors that can result in humans spreading disease. It has been shown that in more than $90 \%$ of the cases, people are the cause of disease transmission among poultry farms. In other words, more than $90 \%$ of breaks in biosecurity are the result of human activity. Thus, if attention is focused on controlling the movement of people, the result may be a significant reduction of disease problems.

\section{Farm Visits: Take Precautions}

Disease outbreaks on poultry farms have been known to follow the path of a careless visitor or employee. World trade and travel are common and this may facilitate even wider spread of disease. A person can visit one farm (perhaps an infected one) in the morning and then visit another farm in other parts of the same country or another country only hours later. Most disease agents can survive during this time frame. For example, it has been shown that Newcastle disease virus (NDV) can survive for several days on the mucous membrane of the human respiratory tract and be isolated from sputum. All people who travel should be aware of this and take precautions to prevent introduction of diseases into their own or clients farms.

1. This document is VM174, one of a series of the Veterinary Medicine-Large Animal Clinical Sciences Department, Florida Cooperative Extension Service, Institute of Food and Agricultural Sciences, University of Florida. Original publication date December 2008. Visit the EDIS Web Site at http://edis.ifas.ufl.edu.

2. Gary D. Butcher, professor and poultry veterinarian, College of Veterinary Medicine, Institute of Food and Agricultural Sciences, University of Florida; Mojtaba Yegani, poultry veterinary consultant, Department of Agricultural, Food and Nutritional Science, University of Alberta, Edmonton, AB; Florida Cooperative Extension Service, Institute of Food and Agricultural Sciences, University of Florida, Gainesville, FL 32611.

The Institute of Food and Agricultural Sciences (IFAS) is an Equal Opportunity Institution authorized to provide research, educational information and other services only to individuals and institutions that function with non-discrimination with respect to race, creed, color, religion, age, disability, sex, sexual orientation, marital status, national origin, political opinions or affiliations. U.S. Department of Agriculture, Cooperative Extension Service, University of Florida, IFAS, Florida A. \& M. University Cooperative Extension Program, and Boards of County Commissioners Cooperating. Larry Arrington, Dean 


\section{Biosecurity and Bosses}

Managers, supervisors and owners are notorious for breaking the very sanitation rules that they require of all employees. Disease agents do not respect authority or ownership. All visitors, regardless of their position in the company, must follow the prescribed protocol which often requires changing clothes or taking showers, wearing coveralls and disinfecting boots. Biosecurity measures apply to everyone within a company.

\section{Work Crews: Continuous Travelers}

Some poultry farm procedures require intermittent use of a crew of workers. There are usually difficulties in assembling a crew that is available and knowledgeable about poultry. Because of this, crews who service many different poultry farms are usually contracted. These people usually travel from one farm to another. The possibility of spreading disease for these crews is high because they visit multiple farms and do not or are not able to take the necessary decontamination precautions. It is best to train farm personnel to do as much of the on-site work as possible and limit visitors only to those times when no alternatives are available.

\section{Neighboring farms: a constant threat}

A common source of infection on a farm is the outbreak of disease at a neighboring farm. It is always wise to avoid visiting neighboring farms when a disease outbreak is occurring in the area. Limiting contact with other poultry farms is important, but even more critical when a disease outbreak is occurring. Often, birds may appear normal, but are actually in the incubation stages of the disease. These birds will be shedding organisms for a period of time before actually exhibiting disease symptoms. Thus, it is wise to treat all farms as contaminated, even those where the birds appear healthy.

\section{Backyard Poultry and Pet Birds: Shedders of Pathogens}

Birds kept as pets or to supply household eggs or meat is capable of carrying and transmitting diseases to commercial poultry farms. Another source of disease spread is related to cock fighting which is common in many parts of the world. Some commercial farm employees might be involved in this type of activity and thus could introduce a serious disease to the poultry enterprise where they are employed. Employees should be especially cautious about contact with backyard birds, migratory waterfowl, wildbirds, and other avian species as pets. These birds can be asymptomatic carriers of pathogens and there is a potential for transmission of pathogens between an employees home and work environments. One careless or uncaring worker can cause a disease outbreak which could jeopardize the jobs of many others.

\section{Hand-washing: A Necessity}

Human hands contaminated with a pathogen can spread disease from one location to another. In order to prevent this, hand-washing amenities should be available to persuade frequent washing of hands before entering and after leaving a poultry house. Research at a human hospital has shown that, as access to a hand-washing facility increased, people became more likely to wash their hands. Hands should be washed with an effective product that does not dry out the skin or cause skin irritation. This is a simple procedure but can play a major role in preventing disease spread.

\section{Group Meetings and Technical Seminars}

When attending essential meetings or seminars where groups of people congregate that have access to poultry: 1) Always shower and change your clothing and footwear before attending a meeting. 2) Drive a vehicle that is not used on your farm. 3) After returning from a meeting, disinfect your vehicle and change your clothing and shoes. These precautions will greatly reduce the potential for the introduction of disease onto the farm.

\section{Periodic Medical Monitoring of Employees}

All farm employees should report to their supervisor when they suffer from gastrointestinal problems. The employee should undergo a medical 
examination and should not be allowed to return to work or have contact with poultry until fully recovered. In some countries, the industry requires the periodic monitoring of employees for salmonellas. This testing may be controversial in some countries and is thus not widely practiced.

\section{Essential Preventive Measures: Points to Remember}

- Do not enter poultry buildings unless absolutely necessary.

- All visitors increase the risk of introduction of diseases onto the farm.

- Have a log book to document anyone entering the premises. This is a good method to help to control people and vehicle traffic and help to identify the culprit if a disease occurs.

- If someone wants to visit a farm, it is necessary to confirm that they have not visited any other farm for at least a few days prior to entering.

- All necessary people who enter the farm should remove street clothes and shoes; take a complete shower; and wear clean coveralls, hats and rubber boots provided by the farm. These practices are normal during a disease outbreak but are often forgotten shortly afterwards.

- Everybody must disinfect boots and wash hands before entering and after leaving each house.

- Practice "shower in -shower out" between farms.

- Do not bring materials and equipment which are not necessary or not easily sanitized into poultry buildings.

- All necessary equipment brought onto a farm from the outside should be decontaminated.

- Farms should consider holding an ongoing employee education program on disease prevention and control, even when there are no disease problems occurring. Setting up a training program after the fact is of little value.
- Investigate all farm workers as much as possible to ensure they do not have contact with birds outside their jobs.

- Do not permit farm personnel to have backyard poultry and pet birds at home. This should be included in the work contract and immediate dismissal should result if violated.

- Discourage farm personnel from bringing fresh meat (especially poultry) and eggs on the farm as part of their lunch.

- Plan farm visits so that younger flocks are visited before older flocks. However, if a younger flock is known to have disease problems it should be visited last and a complete decontamination should be conducted prior to further farm visits.

- Discourage gatherings of employees from different farms of a company.

- Employees should be encouraged to take lunch breaks inside the farm. Traveling to restaurants in groups in cars and making contact with others workers at restaurants will increase the chance of spreading disease. Larger farms have even begun to provide lunches to employees on site.

- Visiting neighboring farms by employees is strictly prohibited. 